\title{
KHẢO SÁT ĐA HÌNH GEN SOD2 C47T VÀ CAT C262T Ở NAM GIỚI VÔ SINH NGUYÊN PHÁT
}

\begin{abstract}
TÓM TẮT
Muc tiêu nghiên cứu: Xác định tỷ lệ đa hình gen SOD2 C47T và CAT C262T ở nam giới vồ sinh nguyên phát bằng kỹ thuật ARMS-PCR, bước đâu xác định mối liên quan giữa đa hình gen SOD2 C47T và CAT C262T với vô sinh nam. Đối tượng và phương pháp nghiên cứu: Áp dụng kỹ thuật $A R M S-P C R$ để xác định đa hình gen SOD2C47T và CAT C262T ở 42 nam giới vô sinh nguyên phát có mật độ tinh dich < 15 triệu tinh trùng/ml và 58 nam giới bình thường có ít nhất 1 con $<5$ tuổi. Kết quả nghiên cứu: Tỷ lệ kiểu gen SOD2 CC/TC/TT ở nhóm nam giới vô sinh lần lượt là $28.5 \%, 40.5 \%, 31 \%$;tỷ lê kiểu gen SOD2 CC/TC/TT ở nhóm chứng lấn lượt là $29.3 \%, 46.6 \%, 24.1 \%$; sự khác biêt giữa 2 nhóm là không có ý nghĩa thống kể với $\mathrm{p}>0.05$; tỷ lệ mang kiểu gen CAT CC/TC/TT ở nhóm nam giới vô sinh lần lượt là $54.7 \%, 42.9 \%$ và 2.4\%;tỷ lệ mang kiểu gen CAT CC/TC/TT ở nhóm bình thường là $77.6 \%, 19 \%, 3,4 \%$;sự khác biệt giữa nhóm nhóm là có ý nghĩa thống kê với $\mathrm{p}<0.05, \mathrm{OR}=2.86$, $95 \% C I=1.203-6.799$. Kết luân: Không có mối liên quan giữa đa hình gen SOD2 C47T với nguy cơ vô sinh ở nam giới, nguy cơ vô sinh ở nhóm nam giới mang đa hình gen CAT C262T cao gấp 2.86 lân nam giới bình thường.
\end{abstract}

Tư khóa: Vô sinh nam, SOD2, CAT.

\section{SUMMARY \\ INVESTIGATION OF SOD2 C47T POLYMORPYSISM AND CAT C262T POLYMORPHISM IN MEN WITH PRIMARY INFERTILITY}

Objectives: Identification of the prevalence of SOD2 C47T polymorphism and CAT C262T polymorphism in primary infertilite men, initial determination of the association between SOD2 C47T polymorphism and C262T CAT polymorphism with male infertility. Subjects and methods: Application of ARMS-PCR in determining SOD2 C47T polymorphism and CAT C262T polymorphism for 42 primary infertile men whose semen concentration less than 15 million sperm $/ \mathrm{ml}$ and 58 healthy men with at least 1 child aged less than 5 years old. Results: In the group of infertile men, the cases with genotype SOD2 CC/TC/TT are 28.5\%, $40.5 \%$, 31\%, respectively, in the control group, the cases with genotype SOD2 CC/TC/TT are 29.3\%, 46.6\%, 24.1\%, respectively, the difference between the 2 groups is

${ }^{1}$ Trường Đại học Y Hà Nội

º̣̂̂nh viện Bưu Điên

Chịu trách nhiệm chính: Nguyễn Thị Trang

Email: Trangnguyen@hmu.edu.vn

Ngày nhận bài: 2.8 .2021

Ngày phản biên khoa hoc: 28.9.2021

Ngày duyệt bài: 4.10 .2021
Lê Thị Quyên', Bạch Huy Anh², Trần Đức Phấn ${ }^{1}$, Nguyễn Thị Trang ${ }^{1}$ not statistically significant with $p>0.05, O R=$; in the group of infertile men, the men withgenotype CAT $\mathrm{CC} / \mathrm{TC} / \mathrm{TT}$ are $54.7 \%, 42.9 \%$ and $2.4 \%$, respectively;in the control group the cases with genotype CAT $\mathrm{CC} / \mathrm{TC} / \mathrm{TT}$ are $77.6 \%, 19 \%, 3,4 \%$, respectively; the difference between the 2 groups was statistically significant with $p<0.05$. Conclusion: There was no association between the SOD2 C47T gene polymorphism and the risk of male infertility, the risk of infertility in the men with CAT C262T polymorphism is 2.86 times higher than healthy men.

Keywords: Male infetility, SOD2, CAT

\section{I. ĐĂT VẤN ĐỀ}

Vô sinh là tình trạng thất bại trong khả năng mang thai sau ít nhất 12 tháng quan hệ tình dục đều đăn không dùng biện pháp tránh thai. ${ }^{1}$ Hiển nay, ước tính trên thế giới có khoảng $15 \%$ các cặp vợ chồng trong độ tuổi sinh sản bị vô sinh, trong đó khoảng $50 \%$ các trường hợp có nguyên nhân đến từ phía nam giới. Tại Việt Nam, tỷ lệ vô sinh các cặp vợ chồng vô sinh khoảng $5 \%$, trong đó vô sinh nam chiếm khoảng 40,8\%. ${ }^{2}$

Gốc tự do là những nguyên tử hoặc phân tử có electron lớp ngoài cùng chưa ghép cặp, thường có xu hướng phản ứng các các phân tử khác để đạt trạng thái ổn định về mặt điện tử. Các mẩu oxy phản ứng (ROS) là các gốc tự do có chứa Oxy. Nhiêu nghiên cứu cho thây các ROS có khả năng gây tổn thương màng tế bào và DNA tinh trùng qua đó ảnh hưởng đến khả năng di động, hình thái của tinh trùng cũng như chức năng sinh sản nam giới. ${ }^{3}$ Để bảo vệ cơ thể khỏi tác động của các ROS, trong cơ thể hình thành hệ thống enzym chống oxy hóagồm NFR2, Catalase, SOD...có khả năng chuyển hóa các ROS thành các chất ít hoặc không gây hại. Các enzym này được mã hóa bởi hệ thống các gen nằm trong nhân tế bào.

Gen SOD2 nằm trên nhánh dài NST số 6 , mã hóa enzym ManganeseSuperoxide dismutase, có chức năng khử gốc superoxide - một ROS có nhiều ở tinh trùng và tinh dịch thành $\mathrm{O}_{2}$ và $\mathrm{H}_{2} \mathrm{O}_{2}$. Đa hình gen SOD2 C47Tgây thay đổi axit amin số 16 Alanin thành Valin, do đó gây giảm hoat độ enzym MnSOD trong tinh dịch dẫn đển giảmchất lượng tinh trùng và tăng nguy cơ vô sinh ở nam giới. ${ }^{4,5}$

CAT nằm trên một gen nằm trên nhánh ngắn NST số 11 , có chức năng mã hóa Catalase, một 
enzym có hoạt độ cao trong tinh trùng và tinh dịch, có khả năng chuyển hóa $\mathrm{H}_{2} \mathrm{O}_{2}$ thành $\mathrm{O}_{2}$ và H2O. Nhiều nghiên cứu cho thấy đa hình gen CAT C 262T có liên quan đến mức stress oxy hóa, khả năng di động, hình thái tinh trùng và nguy cơ vô sinh ở nam giới. ${ }^{5,6}$

\section{II. ĐỐI TƯỢNG VÀ PHƯƠNG PHÁP NGHIÊN CỨU}

2.1. Đối tượng nghiên cứu. Đối tượng nghiên cứu gồm 42 nam giới $\geq 18$ tuổi có mật độ tinh dịch < 15 triệu tinh trùng $/ \mathrm{ml}$, được chẩn đoán vô sinh nguyển phát tại Trung tâm tư vấn Di truyền, Bênh viện Đại học $Y$ Hà Nội từ 7/2020-8/2021, nhóm chứng gồm 58 nam giới bình thường có ít nhất 1 con $<5$ tuổi.

2.2. Phương pháp nghiên cứu. DNA được tách chiết từ máu ngoại vi (chống đông EDTA) bằng kit tách DNA Express của hãng Lytech (Nga).
Sử dụng kỹ thuật ARMS-PCR để xác định các đa hình gen SOD2 C47T và CAT C262T. Kĩ thuật này được thực hiên trên máy CFX96 (BioRad, Mỹ) với chu trình luân nhiệt: $93^{\circ} \mathrm{C}-1$ phút, 35 chu kì $\left(93^{\circ} \mathrm{C}-10 \mathrm{~s}, 64^{\circ} \mathrm{C}-10 \mathrm{~s}, 72^{\circ} \mathrm{C}-20 \mathrm{~s}\right), 72^{\circ} \mathrm{C}$ - 5 phút.

Điện di phát hiện sản phẩm trên thạch agarose $3 \%$ và phân tích kết quả.

Phương pháp xử lý số liệu: Số liệu được xử lý trên phần mềm SpSS 20.0

2.3. Đạo đức nghiên cứu. Các thông tin nghiên cứu hoàn toàn chính xác, trung thực và được chấp thuận bởi cơ quan nghiên cứu.Bệnh nhẩn được thông báo đầy đủ về mục đích nghiên cứu, lợi ích và nghĩa vụ khi tham gia nghiên cứu. Mọi thông tin cá nhân của bệnh nhân đều được giữa bí mật và chỉ sử dụng cho mục đích nghiển cứu.

\section{KẾT QUẢ NGHIÊN CỨU}

\section{1. Đặc điểm tuổi của nhóm đối tượng nghiên cứu}

Bảng 3.1. Độ tuổi trung bình của các đối tượng nghiên cứu

\begin{tabular}{|c|c|c|c|c|c|}
\hline & Nhóm bệnh & Nhóm chứng & t & p & $\mathbf{9 5 \%} \%$ \\
\hline $\mathrm{X} \pm$ SD & $31.81 \pm 7.549$ & $32.72 \pm 5.327$ & -0.508 & 0.613 & $-3.106-1.755$ \\
\hline
\end{tabular}

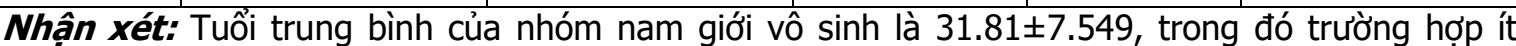
tuổi nhất là 22 tuổi, trường hợp lớn tuổi nhất là 62 tuổi. Tuổi trung bình của nhóm nam giới bình

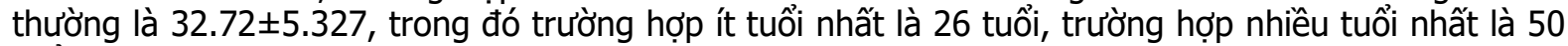
tuổi, sự khác biệt giữa 2 nhóm là không có ý nghĩa thống kê với p>0.05.

3.2. Tỷ lệ đa hình gen SOD2 C47T và CAT C262T ở 2 nhóm đối tượng nghiên cứu

\section{Bảng 3.2. Tỷ lệ đa hình SOD2 C47Tở2 nhóm đôi tượngnghiên cứu}

\begin{tabular}{|c|c|c|c|c|c|c|c|c|}
\hline \multirow{2}{*}{$\begin{array}{l}\text { Kiểu } \\
\text { gen }\end{array}$} & \multicolumn{2}{|c|}{ Nhóm bệnh } & \multicolumn{2}{|c|}{ Nhóm chứng } & \multirow[b]{2}{*}{$\mathrm{X}^{2}$} & \multirow[b]{2}{*}{$\mathbf{p}$} & \multirow{2}{*}{ OR } & \multirow{2}{*}{$95 \% \mathrm{CI}$} \\
\hline & $\mathbf{n}$ & $\%$ & $\mathbf{n}$ & $\%$ & & & & \\
\hline $\mathrm{CC}$ & 12 & $28.5 \%$ & 17 & $29.3 \%$ & & & & \\
\hline TC & 17 & $40.5 \%$ & 27 & $46.6 \%$ & 0.004 & 0.952 & 1.03 & $0.393-2.704$ \\
\hline$\pi$ & 13 & $31 \%$ & 14 & $24.1 \%$ & 0.439 & 0.508 & 1.435 & $0.492-1.484$ \\
\hline $\mathrm{TC}+\mathrm{TT}$ & 30 & $71.5 \%$ & 41 & $70.7 \%$ & 0.118 & 0.732 & 1.169 & $0.48-2.847$ \\
\hline
\end{tabular}

Nhận xét: Trong số 42 nam giới vô sinh, có 12 bệnh nhân (28.5\%) có kiểu gen bình thường (CC), 30 bệnh nhân mang đa hình gen SOD2C47T trong đó 17 (40.5\%) bệnh nhân có kiểu gen dị hợp tử (TC) và 13 bệnh nhân (31\%) có kiểu gen đồng hợp tử (TT).

Trong số 58 nam giới bình thường có 17 (29.3\%) bệnh nhân mang kiểu gen bình thường, 41 bệnh nhân $(70.7 \%)$ mang đa hình gen SOD2C47T trong đó 27 bệnh nhân mang kiểu gen dị hợp (46.6\%) và 14 bệnh nhân (24.1\%) mang kiểu gen đồng hợp. Sự khác biệt giữa 2 nhóm là không có ý nghĩa thống kể với $p>0.05$.

Bảng 3.3. Tỷ lệ đa hình gen CAT C262Tở2 nhóm đôî tượng nghiên cứu

\begin{tabular}{|c|c|c|c|c|c|c|c|c|}
\hline \multirow{2}{*}{ Kiểu gen } & \multirow{2}{*}{\multicolumn{2}{|c|}{ Nhóm bệnh }} & \multicolumn{2}{|c|}{ Nhóm chứng } & \multirow{2}{*}{$\mathrm{X}^{2}$} & \multirow[b]{2}{*}{$\mathbf{P}$} & \multirow{2}{*}{ OR } & \multirow[b]{2}{*}{$95 \% \mathrm{CI}$} \\
\hline & & $\%$ & $n$ & $\%$ & & & & \\
\hline CC & 23 & $54.7 \%$ & 45 & 77.6 & & & & \\
\hline TC & 18 & $42.9 \%$ & 11 & $19 \%$ & 6.647 & 0.01 & 3.202 & $1.298-7.897$ \\
\hline$\pi$ & 1 & $2.4 \%$ & 2 & $3.4 \%$ & 0.000 & 0.986 & 0.987 & $0.084-11.384$ \\
\hline$T C+\pi$ & 19 & $45.3 \%$ & 13 & $22.4 \%$ & 5.832 & 0.016 & 2.86 & $1.203-6.799$ \\
\hline
\end{tabular}

Nhân xét: Trong số 42 nam giới vô sinh, có 23 nam giới (54.7\%) có kiểu gen bình thường CC, 19 nam giới (45.3\%) mang đa hình gen CAT C262T, trong đó có 18 nam giới (42.9\%) có kiểu gen đị hợp TC và 1 nam giới (2.4\%) có kiểu gen đồng hợp TT.

Trong số 58 nam giới bình thường, có 45 (77.6\%) trường hợp mang kiểu gen bình thường CC, 13 
trường hợp (22.4\%) mang đa hình gen CAT C272T, trong đó có 11 trường hợp (19\%) có kiểu gen dị hợp TC, 2 trường hợp (3.4\%) có kiểu gen đồng hợp TT. Sự khác biệt giữa 2 nhóm là có ý nghĩa thống kê với $p<0.05$.

3.3. Mối liên quan giữa đa hình SOD2 C47T, CAT C262T và một số chỉ số tinh dịch đồ. Bảng 3.4. Mối liên quan giữa đa hình SOD2 C47T (SOD2 C47T) và một số chỉ số tinh dịch đồ

\begin{tabular}{|c|c|c|c|c|c|c|c|}
\hline \multicolumn{2}{|c|}{ Chỉ số tinh dịch đồ } & CC (n) & $T C+T T(n)$ & $\mathbf{X}^{2}$ & $\mathbf{p}$ & OR & $95 \% \mathrm{CI}$ \\
\hline Thể tích & $<1.5 \mathrm{ml}$ & 8 & 10 & 2.944 & 0.086 & 0.403 & $0.14-$ \\
\hline Di đông tiến & $<32 \%$ & $\frac{20}{17}$ & $\frac{62}{37}$ & & & & $\frac{1.101}{0.281-}$ \\
\hline tới & $\geq 32 \%$ & 11 & 35 & 0.106 & 0.401 & 0.684 & 1.663 \\
\hline $\begin{array}{l}\text { Hình thái } \\
\text { bình thươnng }\end{array}$ & $\begin{array}{l}<4 \% \\
>4 \%\end{array}$ & $\frac{6}{22}$ & $\begin{array}{l}13 \\
59\end{array}$ & 0.149 & 0.699 & 0.808 & $\begin{array}{l}0.273- \\
2.389\end{array}$ \\
\hline
\end{tabular}

Nhận xét: Ớ nhóm nam giới có kiểu gen bình thường (SOD2 47C), có 8 trường hợp có thể tích tinh dịch ít $(<1.5 \mathrm{ml}), 20$ trường hợp có thể tích tinh dịch bình thường $(\geq 1.5 \mathrm{ml})$. Ở nhóm nam giới mang đa hình gen SOD2 C47T, có 10 trường hợp có thể tích tinh dịch ít $(<1.5 \mathrm{ml}), 62$ trường hợp có thể tích tinh dịch bình thường $(\geq 1.5 \mathrm{ml})$, sự khác biệt giữa 2 nhóm là không có ý nghĩa thống kê với p>0.05.

Ở nhóm nam giới có kiểu gen bình thường (SOD2 47C), có 17 trường hợp có tỷ lệ di động tiến tới $<32 \%$, có 11 trường hợp có tỷ lệ di động tiến tới $\geq 32 \%$. Ở nhóm nam bình thường, có 37 trường hợp có tỷ lệ di động tiến tới <32\%, có 35

trường hợp có tỷ lệ di động tiến tới $\geq 32 \%$, sự khác biệt giữa 2 nhóm là không có ý nghĩa thống kê với p>0.05.

Ở nhóm nam giới có kiểu gen bình thường (SOD2 47C), có 6 trường hợp có tỷ lệ tinh trùng có hình thái bình thường < 4\%, 22 trường hợp có tỷ lệ tinh trùng có hình thái bình thường $\geq 4 \%$. Ở nhóm nam giới mang đa hình gen SOD2 C47T, có 13 trường hợp có tỷ lệ tinh trùng có hình thái bình thường $<4 \%, 59$ trường hợp có tỷ lệ tinh trùng có hình thái bình thường $\geq 4 \%$, sự khác biệt giữa 2 nhóm là không có ý nghĩa thống kê với $p>0.05$.

Bảng 3.5. Mối liên quan giữa đa hình CAT C262T và một số chỉ số tinh dịch đồ

\begin{tabular}{|c|c|c|c|c|c|c|c|}
\hline \multicolumn{2}{|c|}{ Chỉ số tinh dịch đồ } & CC (n) & $T C+T(n)$ & $\mathbf{X}^{2}$ & $\mathbf{p}$ & OR & $95 \% \mathrm{CI}$ \\
\hline Thể tích & $\begin{array}{l}<1.5 \\
\geq 1.5\end{array}$ & $\begin{array}{l}10 \\
58\end{array}$ & $\begin{array}{c}8 \\
24\end{array}$ & 1.562 & 0.211 & 1.933 & $0.68-5.494$ \\
\hline $\begin{array}{l}\text { Di động } \\
\text { tiến tới }\end{array}$ & $\begin{array}{l}<32 \% \\
\geq 32 \% \\
\end{array}$ & $\begin{array}{l}34 \\
34\end{array}$ & $\begin{array}{l}20 \\
12\end{array}$ & 1.369 & 0.242 & 1.667 & $0.706-3.935$ \\
\hline $\begin{array}{l}\text { Hình thái } \\
\text { bình thường }\end{array}$ & $\begin{array}{l}<4 \% \\
\geq 4 \% \\
\end{array}$ & $\begin{array}{l}10 \\
58\end{array}$ & $\begin{array}{c}9 \\
23\end{array}$ & 2.546 & 0.111 & 2.27 & $0.817-6.306$ \\
\hline
\end{tabular}

Nhận xét: Ở nhóm nam giới có kiểu gen bình thường (CAT 262C), có 10 trường hợp có thể tích tinh dịch dưới $1.5 \mathrm{ml}, 58$ trường hợp có thể tích tinh dịch $\geq 1.5 \mathrm{ml}$. Ở nhóm nam giới mang đa hình gen CAT C262T, có 8 trường hợp có thể tích tinh dịch $<1.5 \mathrm{ml}, 24$ trường hợp có thể tích tinh dịch $\geq 1.5 \mathrm{ml}$. Sự khác biệt giữa 2 nhóm là không có ý nghĩa thống kê với p>0.05.

ở nhóm nam giới có kiểu gen bình thường (CAT 262C), số trường hợp có tỷ lệ di động tiến tới <32 và số trường hợp có tỷ lệ di động tiến tới $\geq 32$ là bằng nhau và bằng 34 . Ở nhóm nam giới mang đa hình gen CAT C262T, số trường hợp có tỷ lệ di động tiến tới <32 là 20, số trường hợp có tỷ lệ di động tiến tới $\geq 32$ là 12 . Sự khác biệt giữa 2 nhóm là không có ý nghĩa thống kê với $\mathrm{p}>0.05$.

Ơ nhóm nam giới có kiểu gen bình thường
(CAT 262C), số trường hợp có hình thái bình thường $<4 \%$ là 10 , số trường hợp có hình thái bình thường $\geq 4 \%$ là 58 . Ở nhóm nam giới mang đa hình gen CAT C262T, số trường hợp có hình thái bình thường $<4 \%$ là 9 , số trường hợp có hình thái bình thường $\geq 4 \%$ là 23 . Sự khác biệt giữa 2 nhóm là không có ý nghĩa thống kê với p>0.05

\section{BÀN LUÂN}

Vô sinh là một vấn đề sức khỏe quan trọng, ảnh hưởng lớn đến chất lượng cuộc sống của người bệnh. Trong số các nguyên nhân gây vô sinh, yếu tố nam giới chiếm đến $50 \%$. Chẩn đoán chính xác nguyên nhân gây vô sinh luôn là một yêu cầu cấp thiết trong điêuu trị vô sinh nam. Những năm gần đây, ảnh hưởng đa hình các gen mã hóa enzym chống oxy hóa trong đó có SOD2 C47T và CAT C262T đối với chức năng sinh sản 
của nam giới được rất nhiều tác giả quan tâm, mặc dù đã có nhiều nghiên cứu về các đa hình gen này nhưng mối liên quan giữa chúng với vô sinh nam vẫn chưa rõ ràng. Trong nghiên cứu này, chúng tôi tiến hành xác định tỷ lệ đa hình gen SOD2 C47T và CAT C262T ở nhóm nam giới vô sinh, mối liên quan giữa chúng với vô sinh nam và một số chỉ số tinh dịch đồ.

Trong nghiên cứu này, chúng tôi xác định được trong nhóm nam giới vô sinh, kiểu gen SOD2 47C chiếm $28.5 \%$, đa hình gen SOD2 C47T chiếm $71.5 \%$, trong đó tỷ lệ kiểu gen TC và TT lần lượt là $28.5 \%, 40.5 \%, 31 \%$, không có mối liên quan giữa đa hình gen SOD2 C47T và vô sinh nam với $p>0.05$. Kết quả này tương đồng với nghiên cứu của nghiên cứu của Anaís García Rodríguez và cộng sự (2017): tỷ lệ đa hình gen SOD2 C47T là 78\%, đa hình gen SOD2 C47T không ảnh hưởng đến chức năng sinh sản của nam giới. ${ }^{7} T$ rái ngược với kết quả nghiên cứu của chúng tôi, Guixiang Ji và cộng sự cho rằng, đa hình gen SOD2 C47T làm tăng nguy cơ vô sinh ở nam giới, trong đó kiểu gen đồng hợp TT làm tăng nguy cơ vô sinh lên 2.90 lần và kiểu gen dị hợp TC làm tăng nguy cơ vô sinh lên 1.48 lần so với nam giới bình thường. ${ }^{5}$ Về mối liên quan giữa đa hình gen SOD2 C47T với chất lượng tinh trùng, kết quả nghiên cứu của chúng tôi cho thấy không có mối liên quan giữa đa hình gen SOD2 C47T với khả năng di động và hình thái tinh trùng, kết quả này tương đồng với kết quả nghiên cứu của Hsieh YY và cộng sự. ${ }^{8}$ Ngược lại, kết quả nghiên cứu của Yan $L$ và cộng sựcho rằng đa hình gen SOD2 C47Tcó mối liên quan chặt chẽ với khả năng di động và hình thái tinh trùng. ${ }^{4}$ Sư khác biệt này có thể do nhiều yếu tố như sự khác biệt về đặc tính di truyền, tuổi, cỡ mẫu, ....

Trong nghiên cứu này, chúng tôi xác định được ở nhóm nam giới vô sinh, kiểu genCAT bình thường (CAT CC) chiếm tỳ lệ cao nhất với $54.7 \%$, kiểu gen TC và TT chiếm tỷ lệ thấp hơn với $42.9 \%$ và $2.4 \%$, kết quả này phù hợp với các nghiên cứu khác trên thế giới như nghiên cứu của Anaís García Rodríguez và cộng sự (69\% CC, $26 \% \mathrm{CT}$ và $5 \% \pi T)^{7}$, đa hình gen CAT C262T làm tăng nguy cơ vô sinh lên 3.202 so với nam giới bình thường $(\mathrm{OR}=2.86,95 \% \mathrm{CI}=1.203$ 6.799), kết quả này tương đồng với nghiên cứu của K.G.Savikina: nam giới mang đa hình gen CAT C262T có nguy cơ vô sinh cao gấp 2.7 lần nam giới bình thường. ${ }^{9}$ Trái ngược với kết quả nghiên cứu của chúng tôi, Zini và cộng sự cho rằng không có mối liên quan giữa đa hình gen CAT262T và vô sinh ở nam giới,nghiên cứu của
Anaís García Rodríguez cho kết quả đa hình gen CAT C262T làm tăng hoạt độ Catalase trong tinh dịch, giúp giảm nguy cơ vồ sinh so với nhóm nam giới có kiểu gen bình thường. ${ }^{7}$ Về mối liên quan giữa đa hình gen CAT C262T và các chỉ sô tinh dịch đồ, kết quả nghiên cứu của chúng tôi cho thấy, không có mối liên quan giữa đa hình gen CAT C262T với khả năng di động và hình thái tinh trùng, kết quả này không tương đồng với nghiên cứu của Nour El Houda Bousnane và nghiên cứu của Sabouhi $S$, các nghiên cứu này đềucho rằngcó mối liên quan chặt chẽ giữa đa hình gen CAT C262T với các khả năng di động và hình thái tinh trùng. ${ }^{6} S u^{\prime}$ khác biệt này có thể do nhiều yếu tố như sự khác biệt về đặc tính di truyền, tuổi, cõ̃ mẫu, ....

Những kết quả nghiên cứu trên bước đầu cho thây đa hình gen SOD2 C47T không ảnh hưởng đến chức năng sinh sản nam giới, trái lại đa hình gen CAT C262T làm tăng nguy cơ vô sinh ở nam giới lên 2.86 lần. Tuy nhiên, để khẳng định vai trò của 2 đa hình này đối với vô sinh nam, cần tiến hành thêm nhiêu nghiên cứu với cõ mẫu lớn hơn.

\section{KẾT LUÂ̂N}

Ở nam giới vô sinh nguyên phát, tỷ lệ kiểu gen bình thường (CC), dị hợp (TC) và đồng hợp (TT) lần lượt là $28.5 \%, 40.5 \%, 31 \%$. Không có mối liên quan giữa đa hình gen SOD2 C47T với nguy cơ vô sinh ở nam giới.

Ớ nam giới vô sinh nguyên phát, tỷ lệ kiểu gen bình thường $(\mathrm{CC})$, dị hợp (TC) và đồng hợp (TT) lần lượt là $54.7 \%, 42.9 \%$ và $2.4 \%$. Nguy cơ vô sinh ở nhóm nam giới mang đa hình gen CAT C262T cao gấp 2.86 lần nam giới bình thường.

Lời cảm ơn: Nghiên cứu được thực hiện tại trường Đại học $\mathrm{Y}$ Hà Nội, trong thời gian từ tháng 8/2020 - tháng 6/2021, với sự hỗ trợ của các thây cô tại Bộ môn Y sinh học - Di truyền.

\section{TÀI LIÊU THAM KHẢO}

1. Zegers-Hochschild F, Adamson GD, de Mouzon J, et al. The International Committee for Monitoring Assisted Reproductive Technology (ICMART) and the World Health Organization (WHO) Revised Glossary on ART Terminology, 2009t. Hum Reprod. 2009;24(11):2683-2687. doi:10.1093/humrep/dep343

2. Trân Thị Trung Chiến, Trân Văn Hanh, Phạm Gia Khánh. Nghiên cứu một số vấn đề vô sinh nam giới và lựa chọn kỹ thuật lọc rửa, lưu trữ tinh trùng để điều trị vô sinh. 2002.

3. Henkel RR. Leukocytes and oxidative stress: dilemma for sperm function and male fertility. Asian J Androl. 2011;13(1):43-52. doi:10.1038/aja.2010.76

4. Yan L, Liu J, Wu S, Zhang S, Ji G, Gu A. Seminal superoxide dismutase activity and its relationship with semen quality and SOD gene polymorphism. J 
Assist Reprod Genet. 2014;31(5):549-554. doi:10.1007/s10815-014-0215-2

5. ji G, Gu A, Wang $Y$, et al. Genetic variants in antioxidant genes are associated with sperm DNA damage and risk of male infertility in a Chinese population. Free Radic Biol Med. 2011;52:775-780. doi:10.1016/j.freeradbiomed.2011.11.032

6. Bousnane NEH, May S, Yahia M, Abu Alhaija AA. Association of CAT-262C/T with the concentration of catalase in seminal plasma and the risk for male infertility in Algeria. Syst Biol Reprod Med. 2017;63(5):303-310. doi:10.1080/19396368.2017.1318187

7. García Rodríguez $A$, de la Casa M, Johnston S, Gosálvez J, Roy R. Association of polymorphisms in genes coding for antioxidant enzymes and human male infertility. Ann Hum Genet. 2019;83(1):63-72. doi:10.1111/ahg.12286

8. Hsieh $\mathbf{Y - Y}$, Sun $\mathbf{Y}-\mathrm{L}$, Chang $C-C$, Lee $\mathbf{Y}-\mathbf{S}$, Tsai H-D, Lin C-S. Superoxide dismutase activities of spermatozoa and seminal plasma are not correlated with male infertility. J Clin Lab Anal. 2002;16(3):127-131. doi:10.1002/jcla.10029

9. Savikina KG, Abd Ali AH, Shkurat TP, Lomteva SV, Karantysh GV. Association of CAT C262T (rs1001179) polymorphism with male infertility: Meta-analysis. Meta Gene. Published online September 10, 2021:100974. doi:10.1016/j.mgene.2021.100974

\section{NGHIÊN CỨU TỶ LÊ POLYP ĐAI TRỰC TRÀNG UNG THƯ THEO KÍCH THƯỚC}

\section{TÓM TẮT}

Mục tiêu "Nghiên cứu mối liên quan giữa tuổi, hình ảnh nối soi với kích thước polyp đai trức tràng ung thư". Đối tượng và phương pháp nghiên cứu: Nghiên cứu tiến cứu, mô tả, cắt ngang. Trên 284 bệnh nhân với 362 polyps bao gồm 13 polyp ung thư tại Bênh viện Bạch mai, thời gian từ 8/2020 đến 8/202i. Kết quả: Tuổi trung bình của bệnh nhân polyp ung thư là 64 (nhỏ nhất 32, lớn nhất 85 tuổi). Trong nghiên cứu này kích thước polyps $<10 \mathrm{~mm}$ không ghi nhâanpolyp ung thư. Kích thước trung bình polyp ung thư là 24,38 $\pm 9,87 \mathrm{~mm}$ (nhỏ nhất $10 \mathrm{~mm}$, lớn nhất $50 \mathrm{~mm}$ ). Polyps ung thư chủ yếu ở đại tràng sigma và trực tràng: $46,2 \%$ và $38,5 \%$. Tỷ lể polyps ung thư theo kích thước: $10-19 \mathrm{~mm} 3,96 \%, 20-29 \mathrm{~mm}$ $11,42 \%$ và $\geq 30 \mathrm{~mm} 25 \%$. $92,3 \%$ polyps ungthư ở bệnh nhân $\geq 40$ tuổi. Kết luận: Polyp đại trực tràng được xem là tổn thương tiền ung thư', nên nội soi đại trưc tràng tầm soát ung thư ở người $\geq 40$ tuổi, kể cả người không có dấu hiệu chỉ điểm. Nên cắt polyp đại trực tràng, đặc biệt những polyps có kích thước $\geq$ $10 \mathrm{~mm}$.

Tư khóa: Nội soi đại tràng, polyp đại trực tràng.

\section{SUMMARY}

\section{STUDY THE RATIO OF COLORECTAL CANCEROUS POLYPS ACCORDING TO THE SIZE OF POLYP}

Aims "Study on the relationship of age,

\footnotetext{
${ }^{1}$ Trung tâm Tiêu hóa - Gan mật, Bệnh viện Bạch mai, ${ }^{2}$ Trướng Đại học Y Hà nọi

${ }^{3}$ Bênh viên Đa khoa Hưng Hà, Hưng yên

Chịu trách nhiệm chính: Nguyễn Trường Sơn

Email: Nguyentruongsonbm@yahoo.com

Ngày nhận bài: 3.8.2021

Ngày phản biên khoa hoc: 28.9.2021

Ngày duyệt bài: 5.10 .2021
}

Nguyễn Trường Sơnn', Hoàng Mai Hương², Đỗ Khắc Trường ${ }^{3}$, Đinh Thanh Tuấn ${ }^{2}$

endoscopic image with cancerous colorectal polyps according to the size of polyps". Research Patients and methods: A prospective, descriptive, crosssectional study. Enroll 284 patients with 362 polyps including 13 cancerous polyps at Bach Mai Hospital, from 8/2020 to 8/2021. Results: The average age of patients with cancerous polyps was 64 (the youngest 32 , the oldest 85 years old). In this study, polyp size $<10 \mathrm{~mm}$ without cancerous polyps. Cancerous polyps mainly in the sigmoid colon and rectum: $46.2 \%$ and $38.5 \%$. The average size of cancerous polyps is 24.38 $\pm 9.87 \mathrm{~mm}$ ( $10 \mathrm{~mm}$ minimum, $50 \mathrm{~mm}$ maximum). The percentage of cancerous polyps according to size: 10 $19 \mathrm{~mm} 3.96 \%, 20-29 \mathrm{~mm} 11.42 \%$, and $\geq 30 \mathrm{~mm} 25 \%$. $92.3 \%$ cancerous polyps in patients $\geq 40$ years old Conclusions: Colorectal polyps are considered premalignant lesions, so colonoscopy to screen for cancer in people $\geq 40$ years old, including those asymptomatic. Colorectal polyps should be removed, especially polyps $\geq 10 \mathrm{~mm}$.

Keywords: Colonoscopy, colorectal cancerous polyps.

\section{I. ĐẶT VẤN ĐỀ}

Polyp đại trực trànglà phần nhô ra bất thường của niêm mạc vào trong lòng đại trực tràng ${ }^{1}$, một bệnh lý phổ biến ở Việt Nam cũng như trên thế giới $i^{2,3}$. Hầu hết các ung thư đại trực tràng được phát triển từ polyp tuyến của đại trực tràng, từ lúc nhỏ đến loạn sản và cuối cùng tiến triển thành ung thư. Do đó, polyp đại trực được xem là tiền ung thư, đặc biệt với những polyp có kích thước lớn. Nội soi đại tràng cùng mô bệnh học của polyp cho chúng ta biết được vị trí, kích thước và bản chất của polyp, qua đó nhà lâm sàng đưa ra quyết định điêu trị và tiên lượng một cách chính xác hơn. Vì vậy, chúng tôi nghiên cứu đề tài với mục tiêu: Nghiên cứu mối liên 